\title{
Interaction of plant and soil phenol with Cu pollution
}

\author{
A. Oess ${ }^{1}$, M.V. Cheshire ${ }^{2}$, L. Spack ${ }^{1}$ and J.C. Vedy ${ }^{1}$ \\ ${ }^{1}$ Institut de Pédologie et de Génie sanitaire, Département de Génie Rural, EPFL, 1015 Lausanne, Switzerland \\ ${ }^{2}$ Macaulay Land Use Research Institute, Craigiebuckler, Aberdeen AB15 8 QH, UK
}

\begin{abstract}
Vaccinium sp., Rhododendron ferrugineum and mosses are the dominant plant groups present on the moraine soils of Barme I, Barme II and Pierrier in the Arpette valley. The amount of odiphenols (ODP) available in plants and susceptible to be released each year to the soil surface was determined by HPLC. The quantity of caffeic acid, catechol and protocatechuic acid present in the leaves ranged between 25 and $250 \mathrm{mg} / \mathrm{m}^{2}$. The impact caused by $\mathrm{Cu}$ pollution on this type of ecosystems was studied by a chemical speciation approach. Potentiometric alkaline titrations were carried out on synthetic phenol solutions containing increasing $\mathrm{Cu}$ concentrations. Cu complexation increased with an increasing $\mathrm{pH}$, but in order to have all the $\mathrm{Cu}$ in the complexed form a minimum ratio of $(4: 1)$ ODP-Cu in the solution was necessary.
\end{abstract}

\section{Introduction}

High $\mathrm{Cu}$ contents exceeding by tenfold the values recommended by the Swiss legislation (9) are commonly found in Swiss soils of the lemanic basin. They are mainly due to the extensive use of $\mathrm{Cu}$ containing fungicides for the treatment of vineyards and orchards, wastes from the watch industry and the construction field, which uses $\mathrm{Cu}$ for the fabrication of roofs and gutters. Unpolluted sites become more and more restricted to the confined mountainous and alpine areas. The only exogenous input of pollutants in alpine valleys comes from atmospheric inputs and so far these inputs are not decreasing. In order to study the impact of $\mathrm{Cu}$ pollution on these "natural" sites, we chose to focus our study on chelating agents, which would control the fate of $\mathrm{Cu}$ in the soil and soil solution. Hydrosoluble phenols were selected for our study because they are less prone to degradation than other metabolites, as sugars and amino acids, and have a longer life in soils. A previous study carried out on a range of phenolic compounds bearing different substituents showed that the strongest interaction between $\mathrm{Cu}$ and phenols was obtained with o-diphenols (ODP) [8]. So far, the quantity of these phenols released to the soil by different plant types and their interaction with increasing $\mathrm{Cu}$ concentrations is not known. The aim of this study was to determine the impact of $\mathrm{Cu}$ pollution on the ecosystem by focusing on the chemical speciation properties of the metal. A two-scale approach including a landscape and a molecular scale was considered. Phenols from different plant species were characterised in situ on three different moraine soils in order to elaborate an ODP map of the vegetation. $\mathrm{Cu}$ speciation was studied with pure synthetic ODP solutions under controlled temperature and $\mathrm{pH}$ conditions.

\section{Site description: Alpine soils and plants}

A study site remote from all industrial activities was needed for our study. The Arpette Valley, which was located $15 \mathrm{~km}$ south of Martigny, corresponded to this criterion. Three land plots developed on granitic moraines (Barme I, Barme II, Pierrier I) between the altitudes of 2003 and $2166 \mathrm{~m}$ on the $\mathrm{N}-\mathrm{E}$ transect, were delimited (Fig. 1). The soils were rankers, and orthic podzols [2] with different intensities of weathering and acidification. At $2000 \mathrm{~m}$ the average annual temperature was $4.5{ }^{\circ} \mathrm{C}$, the rainfall greater than $2 \mathrm{~m}$ and the snow cover persisted during 6 to 8 months per year. A delay in snow melt of about 1 month was observed between the Barme I and Pierrier I plots, due to an elevation difference of $163 \mathrm{~m}$. The main plant associations were subalpine dwarf shrubs such as RhodoretoVaccinietum and JuniperoArctostaphyletum uva-ursi $[3,5]$.

\section{Plant biomass and species on the moraines}

To establish a phenolic map of the vegetation we proceeded in three different steps. Firstly, we identified the plant species on each selected land plot, secondly we determined their relative abundance, and finally we analysed ODP's in each plant. Land plots of $25 \mathrm{~m}^{2}$ were delineated on each moraine and the plants identified in August and September 1995, 1996, and 1997. The relative abundance of each species was determined on $25 \mathrm{~m}^{2}$ plots by the normalised method of Braun-Blanquet [4]. The potential mass of plants deposited on the soil each year, was determined from the dry weight on $1 \mathrm{~m}^{2}$ plots for 1995 and 1997. The plants were harvested in August and September by cutting them off at 
Table I. Biomass contribution for each plant group after harvest on $1 \mathbf{~ m}^{2}$.

\begin{tabular}{|c|c|c|c|c|c|c|}
\hline \multirow[b]{2}{*}{ Plant groups } & \multicolumn{2}{|c|}{ Barme I (dry weight, g) } & \multicolumn{2}{|c|}{ Barme II (dry weight, g) } & \multicolumn{2}{|c|}{ Pierriers (dry weight, g) } \\
\hline & 1995 & 1997 & 1995 & 1997 & 1995 & 1997 \\
\hline Rhododendron ferr. & 172 & 115 & 142 & 89 & 63 & 18 \\
\hline Vaccinium $s p$ & 205 & 376 & 197 & 158 & 277 & 4 \\
\hline Herbaceous & 13 & 20 & 13 & 18 & 30 & 18 \\
\hline Lichens & 0 & 0 & 0 & 3 & 18 & 5 \\
\hline Mosses & 241 & 244.4 & 202 & 572 & 31 & 34 \\
\hline Empetrum $h$. & 0 & 0 & 80 & 84 & 50 & 121 \\
\hline Lycopodium a. & 79 & 0 & 0 & 0 & 0 & 0 \\
\hline Total plants & 710 & 755 & 634 & 924 & 469 & 202 \\
\hline
\end{tabular}

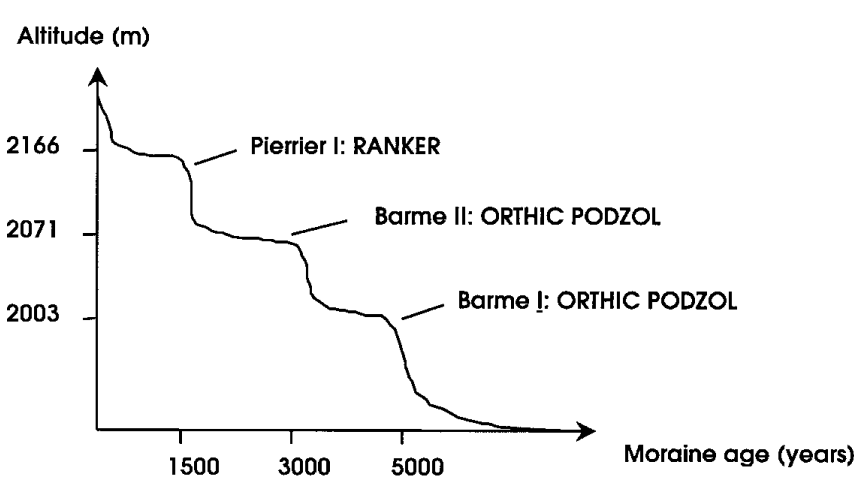

Figure 1. Topochronosequence of the three youngest moraine soils of the Arpette valley.

the root and separating them by species. Mosses and lichens were also collected.

The number of plant species increased from Barme I to Pierrier I, thus increasing with altitude. The abundance-dominance coefficients decreased with altitude. They were highest for Rhododendron ferrugineum and Vaccinium sp. with coefficients ranging between 3 and 4 , and decreasing to 2 on the ranker soil of Pierrier as they were replaced by herbaceous species. Table I shows the contribution in biomass of the different plant groups on the three different moraines. Vaccinium sp., Rhododendron ferrugineum and the mosses contributed to the highest biomass values. The total biomass decreased from Barme I to Pierrier I, thus corresponding to a transition from a dominance of shrubs to an increase in herbaceous plants, which individually weigh less. This transition was attributed to differences in soil properties, which occur between a podzol and a ranker, but also to the adaptation of plants to cooler temperatures and a longer duration of snow cover. A decrease in moss and an increase in lichen biomass were also observed with increasing altitudes, but the contribution from lichens was negligible. Between 1995 and 1997, the biomass contribution was very similar on the Barme I moraine where the vegetation covers more than $80 \%$ of the soil and looks homogeneous. On the higher plots, the difference was more significant. On the Pierriers moraine, such discrepancies were attributed to a distribution of the vegetation in tufts and a portion of naked soil reaching $25 \%$. For the Barme II station, where the vegetation cover reached almost $100 \%$ and looked homogeneous, climatic and topographic reasons could explain the differences observed. Taking a closer look to the shade curves caused by the surrounding peaks, we noticed that the sun penetration was much higher at this particular site, and therefore could cause fluctuations in the $\mathrm{C}$ fixation rate upon important changes in the meteorological conditions.

\section{Phenol analysis}

As the abundance-dominance coefficients and the biomass results showed a predominance of the Vaccinium sp., Rhododendron ferrugineum and mosses, the other plant groups were discarded for the ODP analysis. The procedure of Gallet \& Lebreton [6] was followed to extract phenols from the leaves and adapted to our high performance liquid chromatography (HPLC) system. After crushing the leaves, $2 \mathrm{~g}$ of powder were hydrolyzed in $160 \mathrm{~mL} 2 \mathrm{M} \mathrm{HCl}$ during 45 min at $100{ }^{\circ} \mathrm{C}$. Extractions were then carried out with 3 volumes of ether $(60 \mathrm{~mL}, 60 \mathrm{~mL}, 40 \mathrm{~mL})$ in order to isolate the hydrosoluble monomers. The ether was evaporated on a rotavapor at $40{ }^{\circ} \mathrm{C}$ and a known volume of water not exceeding $30 \mathrm{~mL}$ was added. The aqueous phenol solution was analysed with an 1100 HPLC system from Hewlett Packard coupled to an UV detector $(270 \mathrm{~nm}) .5 \mu \mathrm{L}$ were injected in a $\mathrm{C}_{18}$-column (Vydac TP54: $250 \mathrm{~mm}, 46 \mathrm{~mm}, 5$ $\mu \mathrm{m})$. The following solvents were used: $\mathrm{A}: \mathrm{H}_{2} \mathrm{O}, \mathrm{B}$ : acetonitrile, $\mathrm{C}$ : trifluoroacetic acid. A linear gradient was used 
phenols (mg/m2)

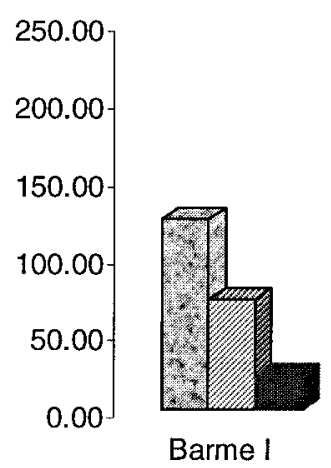

Vaccinium $s p$.
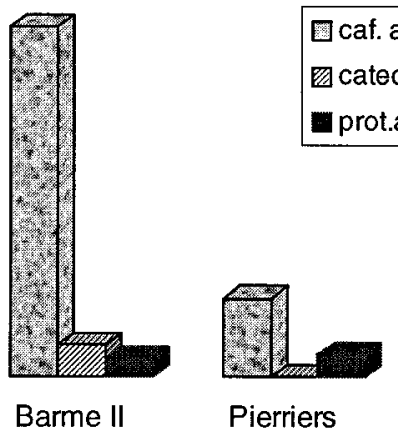

moraines

phenols $(\mathrm{mg} / \mathrm{m} 2)$

Rhododendrum ferr.

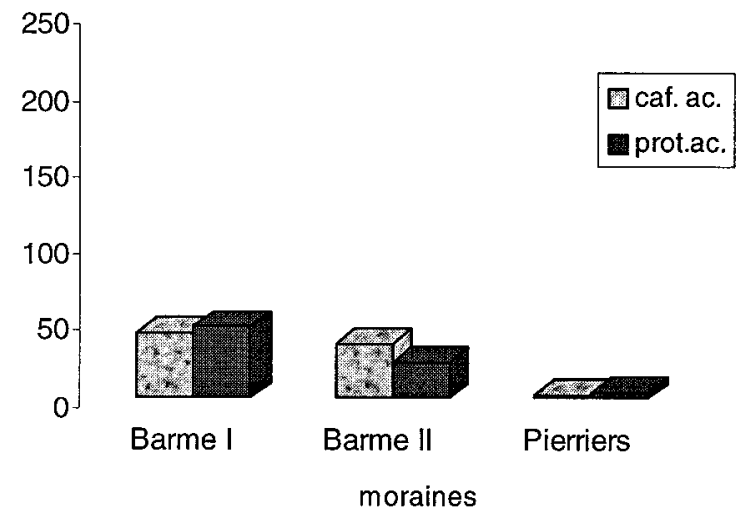

Figure 2. Phenol abundance on the different moraines of the Arpette valley site as extracted from Vaccinium sp. and Rhododendron ferrugineum on $1 \mathrm{~m}^{2}$ plots.

increasing from $0 \%$ to $20 \% \mathrm{~B}$ in $80 \% \mathrm{C}$ followed by a return to the initial conditions in $15 \mathrm{~min}$. The phenolic compounds were identified and quantified by an external standard method using pure caffeic acid, catechol, gallic acid, protocatechuic acid and pyrogallol as reference products. Purity test was carried out with a diode array system.

The total ODP content was two times higher in Vaccinium $s p$. than in Rhododendron ferrugineum thus indicating a higher metabolic activity of these phenols in Vaccinium $s p$. Caffeic acid and protocatechuic acid were the most abundant ODP's. Gallic acid and pyrogallol concentrations were too low to be detected. Catechol was present in Vaccinium sp. but not in Rhododendron ferr. In the mosses only protocatechuic acid was identified at a much weaker concentration. Comparing the phenol concentrations on the different moraines (Graph 1 and 2), a decrease in concentration with altitude was observed for all phenols, except for caffeic acid,

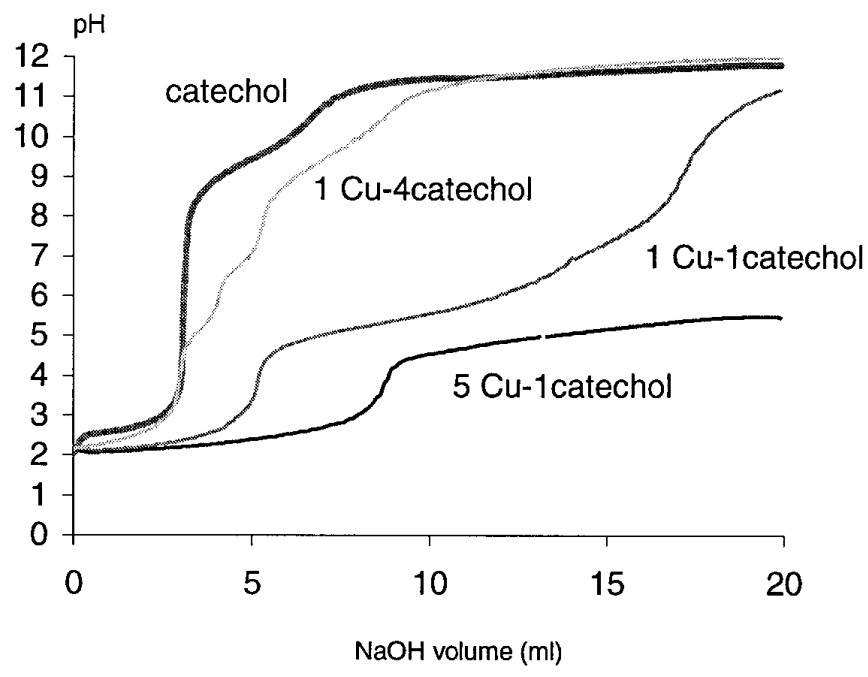

Figure 3. pH complexation domain with increasing $\mathrm{Cu}$ concentrations.

which presented an extremely high value at the Barme II moraine.

\section{$\mathrm{pH}$ and $\mathrm{Cu}$ speciation}

Alkaline potentiometric titration was a simple, rapid and reliable method. It permitted to follow $\mathrm{Cu}$ complexation with phenols continuously over a whole range of $\mathrm{pH}$. The principle of this method was based on the detection of a shift in the titration curve in response to the release of protons following ODP-Cu interaction. Synthetic phenol molecules obtained from Sigma with a purity degree of $99 \%$ were used. Solutions containing $10 \mathrm{mM}$ phenol and 2.5, 10 and $50 \mathrm{mM}$ $\mathrm{CuSO}_{4}$ corresponding to $(4: 1),(1: 1)$ and $(1: 5)$ phenol-Cu ratios were titrated with $0.1 \mathrm{M} \mathrm{NaOH}$ using a Metrohm titroprocessor 686 equipped with a dosimeter 665 and a $\mathrm{pH}$ electrode.

Figure 3, shows the titration curves of catechol alone and catechol in the presence of increasing $\mathrm{Cu}$ concentrations. The shift in the " 4 catechol-1Cu" curve indicated that complexation took place between $\mathrm{pH} 4.5$ and 11. Two additional shoulders appeared in this curve. They were attributed to the presence of two complex species: a mono-bisdentate complex at low $\mathrm{pH}$ and, above $\mathrm{pH} 7$, to a di-bisdentate complex. For the "1catechol: $1 \mathrm{Cu}$ " curve and the " 1 catechol: $4 \mathrm{Cu}$ " curve, the shifts indicated a complexation taking place at an even lower $\mathrm{pH}$. The extra shoulders did not appear indicating that only the mono-bisdentate complex was present.

These results where then compared with the phenol- $\mathrm{Cu}$ ratios obtained in the field, in order to make predictions on the complexation behaviour. In the Arpette valley, the background level of $\mathrm{Cu}$ ranged between $0.4 \mathrm{E}-8$ and $5.6 \mathrm{E}-8$ 
mmoles/g. As the phenol concentrations measured on Barme II was 0.045 mmoles $/ g$, an $\mathrm{ODP}-\mathrm{Cu}$ ratio higher than (1 million: 1) was obtained. For the $\mathrm{pH}$ range of measured in the soil solution ( $\mathrm{pH} 4$ to 6) $\mathrm{Cu}$ would be in mostly be in the bound form. On the other hand, if the $\mathrm{Cu}$ concentration increased to reach the values recommended by the Swiss legislation [9], which are 0.159 mmoles/g dry material for composts and 0.93 mmoles/g for sewage sludge, the ODP-Cu ratio would be inverted and reach (1:3.5) and (1:21) respectively. In this case, for the same $\mathrm{pH}$ range most of the $\mathrm{Cu}$ would be in the free form.

\section{Conclusion}

ODP's can make strong interactions with $\mathrm{Cu}$ ions. The type and the quantity of these phenols released to the soil depended mainly on the plant species present and on the pedo-climatic properties of the site. Vaccinium $s p$. released the highest amount of ODP's on the Barme II moraine with $250 \mathrm{mg} / \mathrm{m}^{2}$ and caffeic acid was the most abundant ODP. Complexation of ODP's mainly depended on the initial phenol concentration, on the $\mathrm{pH}$ and on the ODP-Cu ratio in the solution. When the solution was saturated in phenols, a single ODP molecule was bound to $\mathrm{Cu}$ at low $\mathrm{pH}$, and two ODP's were bound at $\mathrm{pH}$ above 7 . Predictions were made for the field complexation, nevertheless additional parameters would have to be considered, in order to extrapolate these results. In natural solutions other metals and organic ligands are present and may compete and alter the complexation properties and thus the fate of $\mathrm{Cu}$ in the soil phase. Phenols also continue to react and can either disappear or increase in the aqueous medium due to microbial or chemical reactions. At high $\mathrm{pH}$ complexation is followed by a polymerisation of phenols, which in turn leads to a precipi- tation of $\mathrm{Cu}$ [8]. At the opposite, at low $\mathrm{pH}$, even bound to low MW organic ligands, $\mathrm{Cu}$ will remain in the soluble phase and thus be able to migrate in soils.

\section{Acknowledgements}

The authors would particularly like to thank Dr. Nalini Parthasarathy, Rita Bütler, Françoise Okopnik, Corinne Pulfer, Mazen El Alaili and Norberto Benitez for their contributions in this work.

\section{References}

1. Stevenson, F. J. Humus chemistry; Genesis, Composition, Reactions, Wiley-Interscience, NewYork, 1982; pp 443.

2. Baize, D.; Girard, M. C.; A.F.E.S., Référentiel pédologique, INRA, Paris, 1995.

3. Richard, L. Le milieu et la végétation, étude écologique des massifs des Aiguilles Rouges, au Haut-Griffre et des Aravis (Haute Savoie), Annales du Centre, Université de Savoie, 1975; pp 1-100.

4. Braun-Blanquet, J. Pflanzensoziologie: Grundzüge der Vegetationskunde, Springer, Wien, 1964.

5. Bütler, R.; Domergue, F. L. Rev. Ecol. Alp. 1997, 4, 1-12.

6. Gallet, C.; Lebreton, P. Soil Biol. Biochem. 1995, 27, 157-165.

7. Oess, A.; Cheshire, M. V.; McPhail, D. B.; Vedy, J. C. Polymerization: a possible consequence of Copper-phenolic interactions. Accepted for publication in the Proceedings of the Second International Symposium of Mineral-OrganicMicroorganism Interactions, Aug. 14 1997.

8. Oess, A.; McPhail, D. B.; Cheshire, M. V.; Vedy, J. C. Copper complexation with plant derived phenols originating from an alpine ecosystem. Fourth International Conference on the biogeochemistry of Trace Elements. Extended abstract 1997.

9. Osubst. Ordonnance sur les substances dangereuses pour l'environnement. Chancellerie Fédérale, 3000 Berne, Suisse, 1997. 